\title{
Forecasting Share Prices of Small Size Companies in Bursa Malaysia Using Geometric Brownian Motion
}

\author{
Siti Nazifah Zainol Abidin* and Maheran Mohd Jaffar* \\ Department of Mathematics, Faculty of Computer and Mathematical Sciences, Universiti Teknologi MARA, 40450 Selangor, Malaysia
}

Received: 29 May. 2013, Revised: 12 Sep. 2013, Accepted: 13 Sep. 2013

Published online: 1 Jan. 2014

\begin{abstract}
This paper proposes a way to forecast the future closing price of small sized companies by using geometric Brownian motion. Forecasting is restricted to short term investment because most of the investors aim to gain profit in short period of time. This study focusses on small sized companies because the asset prices are lower, hence the asset are affordable for all level of investors. But, to choose the suitable counters to invest is difficult and with the uncertainty of market prices, it will lead to the decline of the investor's confidence level. Therefore, forecasting future closing price is essential. In this paper, we suggest that geometric Brownian motion which involves randomness, volatility and drift can be used to forecast a maximum of two week investment closing prices. This method is accurately proven by the lower value of the Mean Absolute Percentage Error (MAPE). In addition, the uses of data is also investigated and found that one week data is enough to forecast the share prices using geometric Brownian motion.
\end{abstract}

Keywords: Forecasting, geometric Brownian motion, investment, stock market

\section{Introduction}

As investors, they can invest in stocks through Bursa Malaysia, where stocks are bought and sold governed by strict rules, regulations and guidelines. Investment in stock market is a platform for investors to own a share of a company and share both profit and losses of that company. Small sized companies are set up with the lower market capitalization under the range below RM $1,000,000,000$ [1]. This creates opportunities to all level of investors because the asset prices are lower and the company has the opportunity to expand. In addition, small companies will generate high return since prices are more volatile compared to those of medium and big sized companies [2].

More volatile refers to more risk; with unpredictability and uncertainty of market prices, the investors are afraid of investing. Wrong decisions will lead to the loss of capital investment. Forecasting is the best method to use to predict future prices, but the risk of losing is still high because of the possibility of inaccurate forecasting. Thus, our objective is to find the best forecasting method to forecast the future closing prices for short term investment with low percentage error. In addition the number of data used is also considered for investigation. In this area of study concerning predicting stock prices, many mathematical models are used. For example [3] used the combination of the grey model, Fourier series and Markov that produce a new method called Markov-Fourier grey model. The researchers stated that this method can predict accurately but it is only suitable for long-term operation.

Another example is Clustering-Genetic Fuzzy System to forecast the stock prices. The system is outperformed since it gives the lowest Mean Absolute Percentage Error (MAPE) value by comparing with hidden Markov model, hybrid of hidden Markov model, artificial neural network and genetic algorithms, hybrid of hidden Markov model and fuzzy logic, ARIMA and artificial neural network. This model can only be used to predict the next day closing prices [4].

Geometric Brownian motion (GBM) model are used by [5] and [6]. GBM is introduced as a basis for options pricing. A GBM model is a continuous-time stochastic process, explained by [6], in which the logarithm of the randomly varying quantity follows a Brownian motion also known as Wiener process [6]. GBM is used by [6]

\footnotetext{
*Corresponding author e-mail: nazifah4898@yahoo.com.my, maheran@tmsk.uitm.edu.my
} 
to forecast some option prices.

Reference [6] states that GBM is important in the modeling financial process mathematically. It is the derivative of continuous model from discrete model that can be used to predict the movement of the stock prices in the short term period.

This was strongly stated by [7], that the pattern of the stock market's prices is unpredictable and follows the random walk where random walk model in the GBM is outperforming other methods. Thus, in this study, GBM will be used as the method to forecast the future closing prices for small sized companies in Bursa Malaysia and to find the maximum number of day needed so that the prices can be forecasted accurately.

There are some researchers who modify the geometric Brownian motion model such as [5] which demonstrates the development of the modified linear models of geometric Brownian motion by using basic statistics in analyzing stock prices. The modification is done under different data partitioning, with and without jumps. It concludes that the models with jumps are much better than ones without jumps. This modification is not considered in this research as it is not necessary.

In this research the original geometric Brownian motion is applied in analyzing the real stock prices in Bursa Malaysia by looking into the accuracy of the model and the maximum number of days of closing prices needed for forecasting stock prices accurately.

The reason for using the geometric Brownian motion is due to its suitability to forecast the short term investment. The Markov-Fourier grey model could not be used since it is only suitable for long term investment, whereas the Clustering-Genetic Fuzzy System can only be used to predict the next-day investment. A more reliable forecast model that could give more than one-day predicted prices is needed so that the investors can decide immediately and gain profit after the maximum duration of days it can forecast accurately. Thus, the investors will gain more profit after investment even in a short period of time.

This research paper is organized as follows: Section 2 describes the GBM, Section 3 presents the result and Section 4 the conclusion.

\section{Methodology}

The closing prices of the counters are collected daily for a one month period and forecasted for the next one month. This GBM follows the Markov and Martingale properties. Markov properties state that the estimated value of the random variable conditional upon the entire past event, only depends on the previous value. Whereas in the Martingale properties, the conditional expected of winning at any time in the future depends on the amount that is already held [6].

The stochastic differential equation will be particularly important in modeling many asset classes since GBM deals with randomness, volatility, drift and return on investment [6].

According to [6], 'investors' main concern will be on the return on investment which refers to the percentage growth in the value of an asset. If $S_{i}$ is the asset value on the day, then the return from day $i$ to day $i+1$ is given by

$$
R_{i}=\frac{S_{i+1}-S_{i}}{S_{i}}
$$

If $M$ is the number of returns in the sample, then the drift $\mu$ can be represented by the mean of the returns distribution as below:

$$
\mu=\overline{R_{i}}=\frac{1}{M} \sum_{i=1}^{M} R_{i}
$$

The volatility $\sigma$ can be represented by the sample standard deviation as

$$
\sigma=r=\sqrt{\frac{1}{(M-1) \partial t} \sum_{i=1}^{M} R_{i}-\overline{R_{i}}} .
$$

The price of stock at time $t$ is $S(t)$ the random value at time $t$ is $X(t)$, the volatility is $\sigma$ and the drift is $\mu$ forming the stochastic model as follows:

$$
d S=\mu S d t+\sigma S d X .
$$

Suppose the function of $F(S)=\log S$, describes the asset price as the lognormal random walk. By using Ito's Lemma as shown below:

$$
d F=\frac{d F}{d S} d S+\frac{1}{2} \frac{d^{2} F}{d S^{2}} d S^{2}+\cdots
$$

$$
d F=\frac{d F}{d S}[\mu S d t+\sigma S d X]+\frac{1}{2} \frac{d^{2} F}{d S^{2}}[\mu S d t+\sigma S d X]^{2}
$$

It can be simplified to get

$$
d F=\frac{d F}{d S} d S+\frac{1}{2} \sigma^{2} S^{2} \frac{d^{2} F}{d S^{2}} d t
$$

Then by substitution $d S, \frac{d F}{d S}=\frac{1}{S}$ and if $\frac{d^{2} F}{d S^{2}}=-\frac{1}{S^{2}}$ then it will form

$$
\begin{gathered}
d F=\frac{1}{S}[\mu S d t+\sigma S d X]+\frac{1}{2} \sigma^{2} S^{2}\left[\frac{-1}{S^{2}}\right] d t \\
d F=\mu d t+\sigma d X-\frac{1}{2} \sigma^{2} d t
\end{gathered}
$$




$$
d F=\left[\mu-\frac{1}{2} \sigma^{2}\right] d t+\sigma d X
$$

Integration both sides will form

$$
\begin{gathered}
\int d F=\int\left[\mu-\frac{1}{2} \sigma^{2}\right] d t+\int \sigma d X \\
\ln S=\left[\mu-\frac{1}{2} \sigma^{2}\right] t+\sigma(X(t)-X(0)) \\
e^{\ln S}=e^{\left[\mu-\frac{1}{2} \sigma^{2}\right] t+\sigma(X(t)-X(0))+c} \\
e^{\ln S}=e^{\left[\mu-\frac{1}{2} \sigma^{2}\right] t+\sigma(X(t)-X(0))} \cdot e^{c}
\end{gathered}
$$

Here $e^{c}=S(0)$ then the stochastic differential equation for $\log S$ is

$$
S(t)=S(0) e^{\left[\mu-\frac{1}{2} \sigma^{2}\right] t+\sigma(X(t)-X(0))}
$$

The stochastic differential equation is particularly important in the modeling of many asset classes. Equation (5) is the asset price model that is able to predict an asset price at specific time, $t$.

According to [8], there are three measurement of forecasting model which involve time period $t$, The measurements are the number of period forecast $n$ actual value in time period at timet, $Y_{t}$ and forecast value in time period $t, F_{t}$.

The widely used method to evaluate the forecasting method that considers the effect of the magnitude of the actual values is the MAPE. It can be calculated as follows:

$$
M A P E=\frac{\sum\left|\frac{Y_{t}-F_{t}}{Y_{t}}\right|}{n} .
$$

Table 1 shows a scale of judgment of forecasting accuracy using MAPE.

Table 1 A scale of judgment of forecast accuracy

\begin{tabular}{cc}
\hline MAPE & of forecast Accuracy \\
\hline$i 10 \%$ & Highly accurate \\
$11 \%$ to $20 \%$ & Good forecast \\
$21 \%$ to $50 \%$ & Reasonable forecast \\
$>51 \%$ & Inaccurate forecast \\
\hline
\end{tabular}

Source: [8].

The smaller the MAPE value, the more accurate the forecasting model is. By using MAPE formula and applying the scale in Table 1, some judgment of the model can be made.

\section{Results}

There are many small sized companies registered under Bursa Malaysia. This study limits the scope by analyzing the small sized companies with market capitalization under the range of RM 10 million to RM 50 million. There are 89 such companies selected from different sectors in Main Board of Bursa Malaysia.The sectors are construction, industrial products, trading and services, consumer products, infrastructure, properties and technology.

Mulpha Land Berhad, or known as MULPHAL counter in Bursa Malaysia is one example of a company in the property sector. Table 2 is the result of Equation (5) and (6).

Table 2 Forecast and actual prices for MULPHAL counter by using geometric Brownian motion

\begin{tabular}{ccc}
\hline Date & $\begin{array}{c}\text { Forecast } \\
\text { (RM) }\end{array}$ & $\begin{array}{c}\text { Actual } \\
(\mathrm{RM})\end{array}$ \\
\hline 08-Jul-11 & 0.49 & 0.49 \\
11-Jul-11 & 0.48 & 0.49 \\
12-Jul-11 & 0.49 & 0.49 \\
13-Jul-11 & 0.50 & 0.48 \\
14-Jul-11 & 0.49 & 0.48 \\
15-Jul-11 & 0.48 & 0.48 \\
18-Jul-11 & 0.49 & 0.48 \\
19-Jul-11 & 0.49 & 0.48 \\
20-Jul-11 & 0.49 & 0.47 \\
21-Jul-11 & 0.49 & 0.48 \\
22-Jul-11 & 0.47 & 0.47 \\
25-Jul-11 & 0.50 & 0.48 \\
26-Jul-11 & 0.48 & 0.47 \\
27-Jul-11 & 0.47 & 0.45 \\
28-Jul-11 & 0.50 & 0.45 \\
29-Jul-11 & 0.48 & 0.45 \\
01-Aug-11 & 0.49 & 0.47 \\
02-Aug-11 & 0.48 & 0.47 \\
03-Aug-11 & 0.48 & 0.47 \\
04-Aug-11 & 0.48 & 0.46 \\
05-Aug-11 & 0.49 & 0.46 \\
08-Aug-11 & 0.49 & 0.39 \\
09-Aug-11 & 0.49 & 0.39 \\
10-Aug-11 & 0.48 & 0.43 \\
11-Aug-11 & 0.47 & 0.43 \\
12-Aug-11 & 0.49 & 0.43 \\
15-Aug-11 & 0.49 & 0.43 \\
16-Aug-11 & 0.49 & 0.45 \\
17-Aug-11 & 0.48 & 0.45 \\
18-Aug-11 & 0.48 & 0.45 \\
19-Aug-11 & 0.47 & 0.45 \\
\hline
\end{tabular}

Table 2 shows one month (30 days) forecast data prices using GBM and the actual prices of MULPHAL counter. It illustrates that on 8th July 2011 until 22nd of 


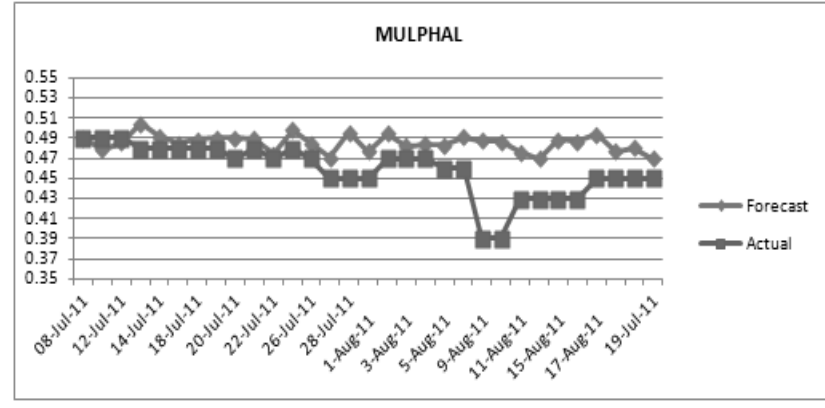

Fig. 1 The graph of forecast vs. actual prices for MULPHAL counter

July 2011, the forecast prices were closed to the actual prices. After 22nd of July 2011, the forecast prices become more volatile and far from the actual prices. This is further illustrated in Figure 1.

Figure 2 provides the graphs of the stock market by comparing the actual prices with the forecast prices.

Let say, an investment was made on 8th July 2011 and gained profit on 22nd July 2011. Thus, from Figure 1 and 2 , we find that after two weeks of working days (on 22nd July 2011) of investment, the forecast price is closest to the actual price.

Next, we focused on the forecast prices of all the 89 counters by looking into the forecast prices on the $22 \mathrm{nd}$ July 2011 and compared with the actual prices on that day. We found that all of the counters were having the forecast prices closest to the actual prices after two weeks of investment. Table 3 illustrates 22 out of 89 counters that show the forecast prices are equal to the actual prices.

Table 3 shows the forecast prices and actual prices on the 22nd July 2011 and MAPE value for two weeks of investment. It shows that most of the MAPE values are less than $10 \%$ and most of the forecast prices are closest to the actual prices [9]. Here, about $77.27 \%$ are highly accurate.

According to Table 3, out of 22 counters, the forecast prices of 17 counters are considered as highly accurate based on the judgment laid out in Table 1.

Next, this study investigates the suitability of data used to forecast the share prices using geometric Brownian motion. The number of data used is one week, two weeks, three weeks, and four weeks. Based on the data obtained, the result is as follows:
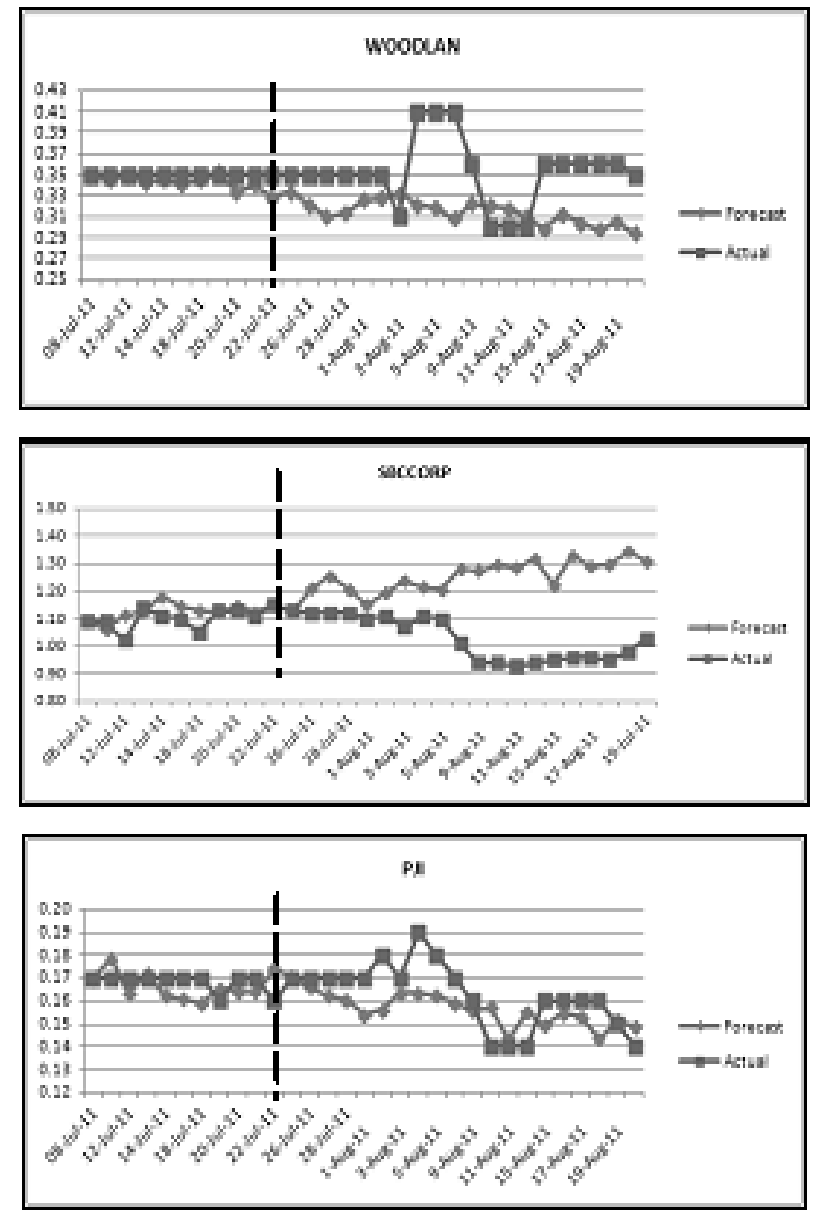

Fig. 2 The other samples of graphs such as WOODLAN, SBCCORP, and PJI counters

Table 4 shows the MAPE value for 22 counters based on the previous data used in geometric Brownian motion. According to Table 4, it shows that the most suitable data to forecast share prices for two-week investment is by using data from previous one week. It shows that the forecast prices of $95.45 \%$ of the counters are highly accurate when one-week data is use. The percentage of $90.91 \%, 86.36 \%$, and $77.27 \%$ of counters are highly accurate for two weeks, three weeks and four weeks data respectively.

The average MAPE value is $5.94 \%, 4.79 \%, 5.89 \%$, and $5.95 \%$ for the data of one week, two weeks, three weeks and four weeks of data used respectively. It shows that the average MAPE for two weeks of data used is the smallest. Although the average MAPE value shows that two weeks is the lowest, but most of the MAPE values give highly accurate value when one week data is used. In conclusion, by using the data gathered of one week, two 
weeks and three weeks are good enough to forecast share prices. On the other hand, if four weeks data was used, most of the forecasted prices may not be highly accurate. This is shown by the highest average of MAPE value and the comparison between the number of weeks and the percentage of highly accurate forecasted share prices. Thus, the short duration of data used is enough to forecast the share prices in Bursa Malaysia by using GBM model. This study also proves the geometric Brownian motion properties on Markov and Martingale properties. These are the advantages of using geometric Brownian motion since the short duration of data used is sufficient to forecast and the formula is easier to be used.

\section{Conclusion}

Investment in small sized companies is an alternative for the investors to generate extra income. With the help of geometric Brownian motion it could increase the investor's confidence level. Geometric Brownian motion is highly accurate as proved by the MAPE value which is lower than $10 \%$. It is a safe model, since most of the forecast prices are much closer to the actual prices in maximum duration of two weeks investment. Thus, the profit can be approximated and decision can be made. This gives the opportunity to the investors to decide whether to buy it immediately and gain profit in the following two weeks or to wait for a better opportunity. In

Table 3 A sample of forecast vs. actual prices and the MAPE value

\begin{tabular}{lccc}
\hline Counters & $\begin{array}{c}\text { Actual } \\
(\mathrm{RM})\end{array}$ & $\begin{array}{c}\text { Forecast } \\
(\mathrm{RM})\end{array}$ & $\begin{array}{c}\text { MAPE } \\
(\%)\end{array}$ \\
\hline BIOSIS & 0.37 & 0.32 & 10.60 \\
DPS & 0.09 & 0.09 & 8.45 \\
SUPERLN & 0.36 & 0.38 & 2.14 \\
SBCCORP & 1.15 & 1.15 & 3.48 \\
WOODLAN & 0.33 & 0.35 & 2.25 \\
EMICO & 0.18 & 0.18 & 5.19 \\
PJI & 0.17 & 0.16 & 4.61 \\
SUPER & 0.82 & 0.84 & 3.61 \\
PJBUMI & 0.20 & 0.22 & 7.53 \\
PRLEXUS & 0.36 & 0.35 & 8.12 \\
SERNKOU & 0.23 & 0.23 & 3.99 \\
HWATAI & 0.50 & 0.52 & 4.40 \\
HOOVER & 0.25 & 0.29 & 12.33 \\
HARVEST & 0.09 & 0.10 & 12.41 \\
MULPHAL & 0.47 & 0.47 & 2.27 \\
FARMBES & 0.70 & 0.70 & 1.69 \\
HINGYAP & 1.69 & 1.66 & 2.22 \\
AMTEL & 0.70 & 0.65 & 10.64 \\
ITRONIC & 0.42 & 0.38 & 4.86 \\
IQGROUP & 0.32 & 0.34 & 2.82 \\
LEESK & 0.09 & 0.08 & 13.19 \\
CAMRES & 0.23 & 0.21 & 4.05 \\
\hline
\end{tabular}

Table 4 The MAPE value of forecast prices with actual prices when using data of different number of weeks.

\begin{tabular}{lcccc}
\hline Counters & One week & Two week & Three Week & Four week \\
\hline BIOSIS & $2.21 \%$ & $2.30 \%$ & $4.09 \%$ & $10.60 \%$ \\
DPS & $8.89 \%$ & $4.72 \%$ & $11.91 \%$ & $8.45 \%$ \\
SUPERLN & $0.00 \%$ & $0.49 \%$ & $7.29 \%$ & $2.14 \%$ \\
SBCCORP & $9.45 \%$ & $2.32 \%$ & $6.78 \%$ & $3.48 \%$ \\
WOODLAN & $9.91 \%$ & $7.36 \%$ & $4.17 \%$ & $2.25 \%$ \\
EMICO & $7.10 \%$ & $7.51 \%$ & $5.12 \%$ & $5.19 \%$ \\
PJI & $2.84 \%$ & $2.76 \%$ & $6.23 \%$ & $4.61 \%$ \\
SUPER & $2.38 \%$ & $5.81 \%$ & $13.87 \%$ & $3.61 \%$ \\
PJBUMI & $2.42 \%$ & $5.75 \%$ & $7.55 \%$ & $7.53 \%$ \\
PRLEXUS & $7.97 \%$ & $10.12 \%$ & $8.04 \%$ & $8.12 \%$ \\
SERNKOU & $6.05 \%$ & $2.43 \%$ & $3.42 \%$ & $3.99 \%$ \\
HWATAI & $7.10 \%$ & $3.45 \%$ & $5.69 \%$ & $4.40 \%$ \\
HOOVER & $6.68 \%$ & $7.96 \%$ & $10.49 \%$ & $12.33 \%$ \\
HARVEST & $29.04 \%$ & $6.47 \%$ & $4.32 \%$ & $12.41 \%$ \\
MULPHAL & $1.71 \%$ & $3.08 \%$ & $2.81 \%$ & $2.27 \%$ \\
FARMBES & $1.88 \%$ & $1.22 \%$ & $2.27 \%$ & $1.69 \%$ \\
HINGYAP & $6.07 \%$ & $5.84 \%$ & $3.49 \%$ & $2.22 \%$ \\
AMTEL & $2.77 \%$ & $1.37 \%$ & $4.78 \%$ & $10.64 \%$ \\
ITRONIC & $7.54 \%$ & $10.57 \%$ & $3.95 \%$ & $4.86 \%$ \\
IQGROUP & $0.92 \%$ & $1.26 \%$ & $2.61 \%$ & $2.82 \%$ \\
LEESK & $1.11 \%$ & $9.93 \%$ & $8.00 \%$ & $13.19 \%$ \\
CAMRES & $6.61 \%$ & $2.63 \%$ & $2.61 \%$ & $4.05 \%$ \\
\hline
\end{tabular}

addition, this paper also shows that the short duration of data used is necessary to forecast the share prices. It will be easier for the investors to use geometric Brownian motion in forecasting share prices. Investing in stock market is risky. Willingness to take the risk will give high returns, because the higher the risk the higher the returns.

\section{Acknowledgement}

This research is funded by the Excellence Fund (EF), Ministry of Higher Education Malaysia managed by the Research Management Institute, Universiti Teknologi MARA Malaysia, 600-RMI/ST/DANA 5/3/Dst (219/2011).

The authors are grateful to the anonymous referee for a careful checking of the details and for helpful comments that improved this paper.

\section{References}

[1] Ong T. S., Teh B. H., Capital Structure and Corporate Performance of Malaysian Construction Sector, International Journal of Humanities and Social Sciences, 1, 28-36 (2011).

[2] Olsen T., The Teenager Investor: How To Start Early, Invest Often and Build Wealth, McGraw Hill Companies Inc., United States of America, (2003).

[3] Hsu Y. T., Liu M. C., Yeh J., \& Hung H. F., Forecasting the tuning time of stock market based on Markov-fourier grey systems, Expert Systems with Application, 36, 8597-8603 (2009). 
[4] Hadavandi, E., Shanvandi, H., \& Ghanbari, A., Integration of genetic fuzzy systems and artificial neural networks for stock price forecasting, Knowledge based Systems, 23, 800808 (2010).

[5] Laddle G. S., \& Wu, L., Development of modified geometric Brownian motion models by using stock price data and basic statistics, Nonlinear Analysis: Theory Methods \& Applications, 71, 1203-1208 (2009).

[6] Wilmott P., Quantitative Finance, John Wiley \& Son, Ltd, Chichester, (2000).

[7] Fama, E., Random walks in stock market prices, Financial Analysis Journal, 51, 1-6 (1965).

[8] Lawrence, K. D., Klimberg R. K., \& Lawrence S. M., Fundamentals of forecasting using excel, Industrial Press Inc., America, (2009).

[9] Siti Nazifah, Z. A., \& Maheran, M. J., Forecasting share prices of small size companies in Bursa Malaysia, Proceeding International Conference of Decision Making (ICDeM 2012), Kedah, Malaysia, 13-16 (2012).

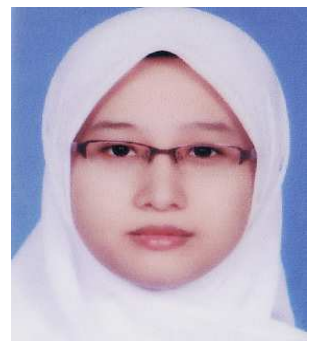

Siti Nazifah Zainol Abidin received her Bachelor Degree in Management Mathematics from Universiti Teknologi MARA Malaysia in 2010. She is currently pursuing her master's degree in Financial Mathematics also in Universiti Teknologi MARA, Malaysia.

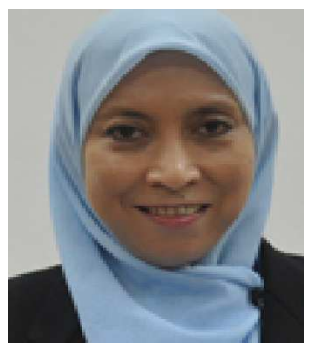

\section{Maheran}

Mohd

Jaffar received her master's degree in Mathematics from California State University - Fresno, USA in 1986 and $\mathrm{PhD}$ in Mathematics from Universiti Kebangsaan Malaysia, Malaysia in 2007. She is currently an associate professor in Universiti Teknologi MARA, Malaysia. Her research interests are in the area of mathematical models in Islamic investment, financial mathematics and ethno mathematics. 